\section{Targeted holistic review of patients' medicines is well overdue}

The authors are right that the evidence base for the long-term benefits of structured medication reviews (SMRs) is not particularly strong. ${ }^{1}$ However, with the publication of the Department of Health and Social Care (DHSC) 'overprescribing' report ${ }^{2}$ any primary care clinician or patient/advocate will tell you that there is much to do to support people to optimise treatments. Why? Because in our time-poor, overstretched $\mathrm{NHS}$, with an ever-increasing number of single organologists' who invariably just add medicines, never subtracting, therefore multiplying the problems, the dedicated time for a real holistic consultation to find out what matters to a person about their medicines and health/wellbeing should not just be welcomed, but cherished.

Poor adherence to medicines and adverse drug reactions, let alone full-blown problematic polypharmacy, are rife. ${ }^{3}$ The general overestimation of the benefits of medicines and an underappreciation of their risks, coupled with imprecise systems for maintaining accurate medicines records across care sectors, also contribute to unnecessary follow-up clinician appointments and medicines waste.

Dr Louisa Polak ${ }^{4}$ is also right that clinicians performing SMRs need to be competent to interpret evidence-based guidance, but also confident enough to disregard it where they and the patient agree that following it does not serve the patient's agenda' and that relational continuity can be particularly important. However, as an experienced clinical pharmacist, who regularly teaches GPs about polypharmacy/deprescribing, I would disagree that clinical pharmacists, the new medicines experts in primary care, cannot perform these SMRs. Yes, some less experienced may need additional training and more GP input to perform SMRs in complex patients with multimorbidity. But then many experienced GPs, who have excellent relationships with patients, also lack the confidence to stop medicines and arguably have more appropriate primary care clinical roles that only they can best perform.
I suggest that Primary Care Networks hone their plans to risk stratify which patients are most in need of an SMR, agree how many clinicians have the competency and time to provide them, then set up the maximum appointment sessions they have the capacity to provide and crack on! Our patients will thank us.

\section{Steve Williams,}

Senior Clinical Pharmacist, Poole Bay and Bournemouth Primary Care Network. Email: stevethechemistlagmail.com

\section{Competing interests}

Department of Health and Social Care, Good for You, Good for Us, Good for Everybody: A Plan to Reduce Overprescribing, 2021, short-life working group member. NHSE/I Network Contract Direct Enhanced Service SMRs, 2019/2020, short-life working group member.

\section{REFERENCES}

1. Stewart D, Madden M, Davies $P$, et al. Structured medication reviews: origins, implementation, evidence, and prospects. Br J Gen Pract 2021; DOI https://doi.org/10.3399/bjgp21X716465.

2. Department of Health and Social Care (DHSC). Good for You, Good for Us, Good for Everybody: A Plan to Reduce Overprescribing to Make Patient Care Better and Safer, Support the NHS, and Reduce Carbon Emissions. London: DHSC, 2021. https://assets.publishing.service.gov.uk/ government/uploads/system/uploads/attachment data/file/1019475/good-for-you-good-for-us-goodfor-everybody.pdf (accessed 11 Nov 2021).

3. Williams S, Brad L. Impact of practice based clinical pharmacist led medication reviews on ambulatory patients with hyper polypharmacy. $\mathrm{Br}$ J Gen Pract 2018; DOI: https://doi.org/10.3399/ bjgp18X697097.

4. Polak L. Structured medication reviews for frail older people should be done by GPs or experienced NPs. [Letter]. Br J Gen Pract 2021; DOI: https://doi.org/10.3399/bjgp21X717149.

\section{Poverty screening in primary care}

Many thanks to Gopal and colleagues for providing a balanced article about poverty screening and for providing guidance to GPs who wish to take this further. ${ }^{1}$ However, we must separate our wish to help individuals facing poverty from our concerns about health inequalities: we cannot resolve the latter by doing the former; that just isn't how health inequalities work.

As healthcare providers, we are potentially more able to intervene usefully in healthcare inequalities (unequal access, experiences, and outcomes of health care) than in the health inequalities caused by unfair social conditions. Still, if we are concerned about inequalities in health, and our role in furthering evidence and understanding of these, then we need to acknowledge the social gradient and move on from thinking purely about people at the bottom'. If our concerns are to be widely shared, it will be when inequalities are recognised to impact everyone. Using a generic socioeconomic marker, such as occupation or education, and collecting this information from everyone, rather than identifying poverty alone, would not only seem fairer and less stigmatising, but would also provide comparative data.

Finally, there is no obvious reason why primary care should be the best place to identify people experiencing poverty or to signpost sources of support. Presumably HM Revenue and Customs and the Department for Work and Pensions already have a good idea of which people are facing poverty. Could they do the signposting? Or could they share information with the Department of Health and Social Care? Could the Royal College of General Practitioners propose this?

Andrew Moscrop,

GP, Luther Street Medical Centre for the Homeless and Vulnerably Housed, Oxford. Email: andrewmoscroplapost.harvard.edu

\section{REFERENCE}

1. Gopal DP, Beardon S, Caraher M, et al. Should we screen for poverty in primary care? Br J Gen Pract 2021; DOI: https://doi.org/10.3399/bjgp21X717317. 